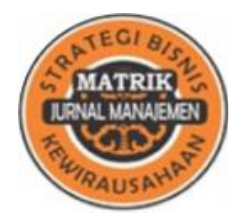

P-ISSN : 1978-2853 E-ISSN : 2302-8890

\section{MATRIK: JURNAL MANAJEMEN, STRATEGI BISNIS DAN KEWIRAUSAHAAN}

Homepage: https://ojs.unud.ac.id/index.php/jmbk/index

Vol. 13 No. 1, Februari 2019, 1-14

\title{
PERAN MEDIASI KNOWLEDGE SHARING PADA PENGARUH QUALITY OF WORK LIFE DAN KEPUASAN KERJA TERHADAP KINERJA KARYAWAN
}

\author{
Ni Luh Putu Surya Astitiani ${ }^{1)}$, Desak Ketut Sintaasih ${ }^{2)}$ \\ ${ }^{1,2)}$ Fakultas Ekonomi dan Bisnis, Universitas Udayana, Bali, Indonesia \\ email: sintaasih@yahoo.com
}

DOI : https://doi.org/10.24843/MATRIK:JMBK.2019.v13.i01.p01

\begin{abstract}
ABSTRAK
Tujuan penelitian ini adalah untuk menganalisis bagaimana peran mediasi knowledge sharing pada pengaruh quality of work life dan kepuasan kerja terhadap kinerja karyawan. Penelitian ini dilakukan di Swastika Bungalows Sanur. Jumlah sampel yang diambil sebanyak 60 karyawan dengan metode sampel jenuh. Data dikumpulkan dengan menyebarkan kuesioner dan menggunakan analisis Partial Least Square (PLS) sebagai teknik analisis data. Hasil dari penelitian ini menunjukkan bahwa quality of work life berpengaruh positif terhadap knowledge sharing, kepuasan kerja berpengaruh positif terhadap knowledge sharing, quality of work life berpengaruh positif terhadap kinerja karyawan, kepuasan kerja berpengaruh positif terhadap kinerja dan knowledge sharing berpengaruh positif terhadap kinerja karyawan, selain itu hasil penelitian ini juga mengungkapkan bahwa knowledge sharing memediasi pengaruh quality of work life terhadap kinerja karyawan dan memediasi pengaruh kepuasan kerja terhadap kinerja karyawan di Swastika Bungalows Sanur. Implikasi praktis penelitian ini adalah diharapkan temuan studi dapat menjadi bahan pertimbangan bagi manajemen Swastika Bungalows Sanur dalam hal meningkatkan kinerja karyawan dengan memperhatikan dukungan dengan memperhatikan suasana kerja yang nyaman, pemberian kompensasi yang adil, dan selalu meningkatkan kepuasan kerja karyawan dan peran knowledge sharing sebagai pemediasi untuk dapat meningkatkan kinerja karyawan.
\end{abstract}

Kata Kunci: quality of work life, kepuasan kerja, knowledge sharing, kinerja karyawan

\section{MEDIATING ROLE OF KNOWLEDGE SHARING ON THE IMPACT OF QUALITY OF WORK LIFE AND JOB SATISFACTION ONEMPLOYEES' PERFORMANCE}

\begin{abstract}
The purpose of this study is to examine the mediation role of knowledge sharing in the influence of quality of work life and work satisfaction on employee performance. This study was conducted on the Swastika Bungalows Sanur. The total sample is 60 employees who were selected with the total population sampling method. The data collection was conducted by distributing questionnaires and the partial least square (PLS) analysis is the data analysis technique. The results of this research showed that quality of work life has a positive influence on knowledge sharing, work satisfaction has a positive influence on knowledge sharing, quality of work life has a positive influence on employee performance, work satisfaction has a positive influence on performance, and knowledge sharing has a positive influence on employee performance. Furthermore, the results of this study also showed that knowledge sharing is able to mediate the influence of quality of work life on employee performance and mediate the influence of work satisfaction on employee performance in Swastika Bungalows Sanur. The practical implication of this study is that this study is expected to be a material for the management of Swastika Bungalows Sanur to consider in improving the performance of employees by providing support such as by maintaining a comfortable work condition, providing fair compensation, and always improve the work satisfaction and the role of knowledge sharing as the mediator to improve employee performance.
\end{abstract}

Keywords: quality of work life, work satisfaction, knowledge sharing, employee performance 


\section{PENDAHULUAN}

Persaingan bisnis yang semakin tajam menyebabkan para pengusaha pariwisata meningkatkan kualitas manajemen perusahaan melalui sumber daya manusia yang dimilikinya. Para pebisnis hotel sadar akan nilai investasi karyawan sebagai sumber daya manusia dimana sumber daya manusia dipandang sebagai aset perusahaan yang penting karena manusia merupakan sumber daya yang dinamis dan selalu dibutuhkan dalam tiap proses produksi baik barang maupun jasa yang dapat mempengaruhi efisiensi dan efektivitas suatu organisasi.

Swastika Bungalows Sanur termasuk salah satu yang merasakan dampak dari pesatnya perkembangan pariwisata saat ini. Fenomena yang ditemukan di Swastika Bungalows Sanur dimana dari hasil wawancara manager menyampaikan bahwa kinerja karyawan mulai menurun dengan seringnya karyawan yang bolos pada saat jam kerja dan kurangnya komunikasi antar atasan serta karyawan. Funmilola, Sola dan Olusola (2013) menyatakan bahwa dimensi kepuasan kerja berkontribusi positif dan signifikan terhadap kinerja karyawan, sedangkan hasil yang berbeda diungkapkan oleh Ahmad, Khursheed, dan Idrees (2010) yang menyebutkan bahwa kepuasan kerja dan kinerja karyawan memiliki hubungan yang lemah.

Berdasarkan latar belakang yang telah diuraikan, maka tujuan penelitian ini adalah untuk mengetahui peran mediasi knowledge sharing pada pengaruh quality of work life dan kepuasan kerja terhadap kinerja karyawan.

Knowledge based view (KBV) Teece, Pisano, and Shuen, (1997) menjadi theory dalam penelitian ini. Teori ini digunakan untuk memperjelas bagaimana pengaruh kepuasan kerja karyawan terhadap kinerja karyawan dengan knowledge sharing sebagai variabel mediasi. Pendekatan KBV dapat membentuk dasar untuk membangun keterlibatan modal manusia dalam kegiatan rutin dalam perusahaan. Hal tersebut dapat dicapai melalui peningkatan keterlibatan karyawan dan kinerja karyawan dalam merumuskan tujuan operasional baik jangka pendek, menengah dan jangka panjang. Penelitian ini juga didukung oleh kajian empiris mengenai quality of work life, kepuasan kerja, knowledge sharing dan kinerja karyawan.

Kinerja adalah konsep multikomponen pada tingkat dasar seseorang yang dapat dibedakan melalui aspek proses kinerja, yaitu perilaku dari hasil yang diharapkan (Borman dan Motowidlo, 1993; Campbell, 1993; Roe, 1999). Kinerja karyawan telah dipelajari dalam psikologi industry maupun organisasi terutama yang berhubungan dengan tempat kerja (Abdullah, Ismail, dan Idrus, 2015). Bagi organisasi yang mampu mengelola sumber daya manusia dan mampu mengoptimalkan kemampuan SDM cenderung menghasilkan karyawan yang memiliki kinerja yang baik sehingga berimplikasi pada pencapaian tujuan organisasi.

Pengetahuan adalah hal yang sangat fundamental dalam organisasi karena pengetahuan memiliki hubungan yang sangat kuat dengan kesuksesan organisasi (Nonaka dan Takeuchi, 1995). Knowledge sharing adalah proses pemindahan keterampilan dan kemampuan antar karyawan (Lin, 2007). Hasil studi yang dilakukan oleh Jordan dan Jones (1997) mengatakan bahwa proses knowledge sharing berpengaruh pada kesuksesan dan keuntungan organisasi terutama dalam kepemilikan dan peningkatan modal intelektual dan kesuksesan organisasi.

Quality of work life adalah suatu cara pikir tentang orang-orang, pekerjaan, dan organisasi yang memusatkan perhatian pada dampak pekerjaan terhadap pekerja dan efektivitas organisasional, disamping memberikan gagasan-gagasan partisipatif dalam memecahkan masalah-masalah organisasional dan pembuatan keputusan (Anatan dan Ellitan, 2007). Walton (1998) mendefinisikan quality of work life sebagai reaksi personalia untuk bekerja terutama hasil penting dalam kaitannya dengan pekerjaan kebutuhan kepuasan dan kesehatan psikologis. Quality of work life mengacu pada keadaan menyenangkan tidaknya lingkungan pekerjaan bagi orang-orang (Davis dan Newstorm, 2006).

Kepuasan kerja merupakan sebuah konsep yang dapat didefinisikan dari sudut pandang yang beragam. Locke (1976:309) mengemukakan bahwa kepuasan kerja adalah sebuah sikap senang atau kondisi emosi yang positif sebagai hasil dari penilaian pekerjaan maupun pengalaman terhadap pekerjaan. Robbins dan Judge (2001) menyebutkan kepuasan kerja sebagai suatu sikap umum terhadap pekerjaan seseorang, selisih antara banyaknya ganjaran yang diterima seorang pekerja dan banyaknya yang mereka yakni seharusnya mereka terima.

Cascio (2013) mendefinisikan quality of work life sebagai persepsi karyawan tentang kesejahteraan mental dan fisiknya ketika bekerja. Quality of work 
life merupakan suatu cara pikir tentang orang-orang, pekerjaan, dan organisasi. Dehaghi (2014) dalam penelitiannya menyebutkan bahwa hubungan yang signifikan ditemukan antara quality of work life manajer perawat dan partisipasi mereka dalam menerapkan strategi manajemen pengetahuan. Korelasi kuat ditemukan antara penerapan manajemen pengetahuan dan partisipasi manajer perawat dalam pengambilan keputusan.

Zadeh (2016) meneliti hubungan antara quality of work life, kepuasan hidup dan manajemen pengetahuan pada guru sekolah menengah kedua. Hasil penelitian ini menunjukkan bahwa ada hubungan langsung antara quality of work life dengan knowledge management. Penelitian ini penting dilakukan untuk memberikan pemahaman yang jelas mengenai inkonsistensi pada hasil penelitian sebelumnya, sehingga dapat dirumuskan hipotesis sebagai berikut:

\section{$\mathrm{H}_{1}$ : Quality of work life berpengaruh positif terhadap knowledge sharing di Swastika Bungalows Sanur}

Penelitian yang menunjukan hubungan antara kepuasan kerja dengan knowledge sharing dilakukan oleh Suliman dan Al-Hosani (2014) menemukan hubungan langsung secara signifikan. Praktek knowledge sharing merupakan hasil dari kepuasan kerja karyawan dalam organisasi. Hal ini memberikan implikasi bahwa kepuasan kerja membuat karyawan mau berbagi pengetahuan terhadap karyawan lain. Abdullah, Ismail, dan Idrus (2015) menemukan bahwa terdapat hubungan langsung antara kepuasan kerja dengan praktek berbagai pengetahuan antara akademisi di Malaysia. Hasil kontradiktif ditemukan oleh studi Husain dan Husain (2014) serta Muleta (2014) yang menyatakan bahwa kepuasan kerja tidak berpengaruh signifikan terhadap knowledge sharing. Penelitian ini penting dilakukan untuk memberikan pemahaman yang jelas mengenai inkonsistensi pada hasil penelitian sebelumnya, sehingga dapat dirumuskan hipotesis sebagai berikut:

$\mathrm{H}_{2}$ : Kepuasan kerja karyawan berpengaruh positif terhadap knowledge sharing di Swastika Bungalows Sanur.

Quality of work life merupakan gambaran dari sikap hidup yang berkualitas yang selalu memandang perilaku dari sudut yang positif, sementara kepuasan kerja sendiri merupakan gambaran dari sikap atas pandangan terhadap hasil pekerjaan yang telah dilakukan oleh seseorang. Pengaruh quality of work life terhadap kinerja karyawan secara parsial adalah positif dan signifikan (fathiyah dan Alex, 2017). Frediyan, Nurul, dan Nuraida (2017) mengungkapkan hubungan antara quality of work life dengan kepuasaan kerja dan kinerja karyawan adanya masalah mengenai tingginya angka absensi yang menunjukkan ketidaksiplinan karyawan maka dilakukan analisis lebih lanjut mengenai hubungan antara komponen quality of work life dengan produktiivitas kerja karyawan. Penelitian ini penting dilakukan untuk memberikan pemahaman yang jelas mengenai inkonsistensi pada hasil penelitian sebelumnya, sehingga dapat dirumuskan hipotesis sebagai berikut:

\section{$\mathrm{H}_{3}$ : Quality of work life berpengaruh positif terhadap kinerja karyawan di Swastika Bungalows Sanur}

Kepuasan kerja merupakan keadaan emosional karyawan memandang pekerjaan mereka. Karyawan yang tidak memperoleh kepuasan kerja tidak akan pernah mencapai kematangan psikologis, dan pada gilirannya akan menjadi frustrasi. Sedangkan karyawan yang mendapatkan kepuasan kerja biasanya mempunyai catatan kehadiran dan perputaran yang lebih baik, kurang aktif dalam kegiatan serikat karyawan, dan berprestasi lebih baik dari pada karyawan yang tidak memperoleh kepuasan kerja (Kurniawan, 2018). Studi empirik yang dilakukan oleh Funmilola, Sola, and Olusola. (2013) mengatakan bahwa dimensi kepuasan kerja yang terdiri dari pay, supervision, promotion, work it self dan work condition berkontribusi positif dan signifikan terhadap kinerja karyawan. Arsiyati (2013) Kepuasan Kerja berpengaruh terhadap kinerja karyawan. Triyono (2011) menunjukkan bahwa kepuasan kerja berpengaruh positif terhadap kinerja pegawai. Karyawan dengan kepuasan kerja tinggi akan menunjukkan sikap yang positif terhadap pekerjaan mereka. Karyawan akan fokus dan bersungguh-sungguh dalam menjalankan pekerjaannya. Hal ini didukung oleh Shaju \& Subhashini (2017) yang menyatakan adanya hubungan positif antara dimensi kepuasan kerja dan kinerja karyawan. Tetapi terdapat hasil yang berbeda oleh 
Setyaningdyah et al. (2013) menemukan bahwa kepuasan kerja tidak berpengaruh signifikan terhadap kinerja karyawan. Penelitian ini penting dilakukan untuk memberikan pemahaman yang jelas mengenai inkonsistensi pada hasil penelitian sebelumnya, sehingga dapat dirumuskan hipotesis sebagai berikut:

$\mathrm{H}_{4}$ : Kepuasan kerja berpengaruh positif terhadap kinerja karyawan di Swastika Bungalows Sanur

Peranan knowledge sharing sangat penting dalam kehidupan organisasi dalam rangka meningkatkan produktivitas dan kompetensi karyawan (Kurniawan, 2018). Knowledge sharing dapat meningkatkan keahlian dan motivasi kerja sehingga mendorong peningkatan kinerja individu dan organisasi. Kinerja karyawan akan mencapai hasil lebih maksimal apabila didukung knowledge (pengetahuan) yang dimilikinya. Hasil studi yang dilakukan oleh Akram dan Bokhari (2011) menyebutkan bahwa karyawan dalam berbagi pengetahuan dengan karyawan lain berawal dari motivasi dan kerelaan untuk melakukannya sehingga mampu meningkatkan kinerja. Secara spesifik studi yang dilakukan oleh Ozlen (2015) menyatakan bahwa knowledge sharing. Wang dan Wang (2012) mengatakan bahwa knowledge sharing memiliki hubungan langsung yang positif dengan kinerja karyawan. Sejalan dengan hal tersebut hasil studi Masa' deh (2015) juga menemukan hubungan positif dan signifikan antara knowledge sharing dan kinerja karyawan. Hasil kontradiktif disajikan oleh studi widianto (2015) bahwa knowledge sharing tidak berpengaruh signifikan terhadap kinerja karyawan. Penelitian ini penting dilakukan untuk memberikan pemahaman yang jelas mengenai inkonsistensi pada hasil penelitian sebelumnya, sehingga dapat dirumuskan hipotesis sebagai berikut:

$\mathrm{H}_{5}$ : Knowledge sharing berpengaruh positif terhadap kinerja karyawan di Swastika Bungalows Sanur.

Knowledge sharing hanya dapat dilakukan bilamana setiap anggota memiliki kesempatan yang luas dalam menyampaikan pendapat, ide, kritikan, dan komentarnya pada anggota lain (Subagyo, 2007) pada (Herjianto, 2008) dalam penerapannya knowledge sharing membutuhkan media yang mendukung. Raskov (2007) memberi pengertian knowledge sharing terjadi antar individu dalam suatu komunitas, dimana individu berinteraksi dan berbagi pengetahuan dengan individu lainya melalui ruang maya atau tatap muka, Community of Practice (CoP), group, forum dan sejenisnya. Sehingga unit analisis dalam knowledge sharing adalah individu. Knowledge sharing menolong para karyawan untuk menyelesaikan masalahmasalah yang pelik di dalam pekerjaannya seharihari. Dapat dikatakan bahwa knowledge sharing mempunyai peran sebagai variabel pemediasi antara quality of work life dengan kinerja karyawan. Hal senada diungkapkan juga oleh Dharma (1985) dalam (Arisman, 2007) bahwa kinerja adalah suatu yang dikerjakan atau produk/jasa yang dihasilkan atau atau diberikan seseorang atau sekelompok orang. Penelitian ini penting dilakukan untuk memberikan pemahaman yang jelas mengenai inkonsistensi pada hasil penelitian sebelumnya, sehingga dapat dirumuskan hipotesis sebagai berikut:

$\mathrm{H}_{6}$ : Knowledge sharing memediasi pengaruh kepuasan kerja karyawan terhadap kinerja karyawan di Swastika Bungalows Sanur.

Studi yang dilakukan oleh Tong et al. (2014) menyebutkan bahwa knowledge sharing memainkan peran penting sebagai variabel mediator hubungan antara budaya organisasi dan kepuasan kerja pada praktisi ICT di Hongkong. Dalam studi tersebut juga disebutkan bahwa peran budaya organisasi sangat kecil secara statistik pada kepuasan kerja karyawan, jadi dengan memasukan variabel knowledge sharing maka hubungan budaya organisasi terdapat kepuasan kerja menjadi lebih besar dan signifikan. Saeed (2016) juga menunjukkan bahwa terdapat pengaruh signifikan dari kepuasan kerja dan knowledge sharing terhadap kinerja karyawan di industri minyak dan gas. Penelitian Fadlallh (2015) juga menunjukkan bahwa ada pengaruh positif dan signifikan secara statistik antara faktor kepuasan kerja dengan kinerja karyawan. Penelitian ini penting dilakukan untuk memberikan pemahaman yang jelas mengenai inkonsistensi pada hasil penelitian sebelumnya, sehingga dapat dirumuskan hipotesis sebagai berikut:

$\mathrm{H}_{7}$ : Knowledge sharing memediasi pengaruh kepuasan kerja karyawan terhadap kinerja karyawan di Swastika Bungalows Sanur. 


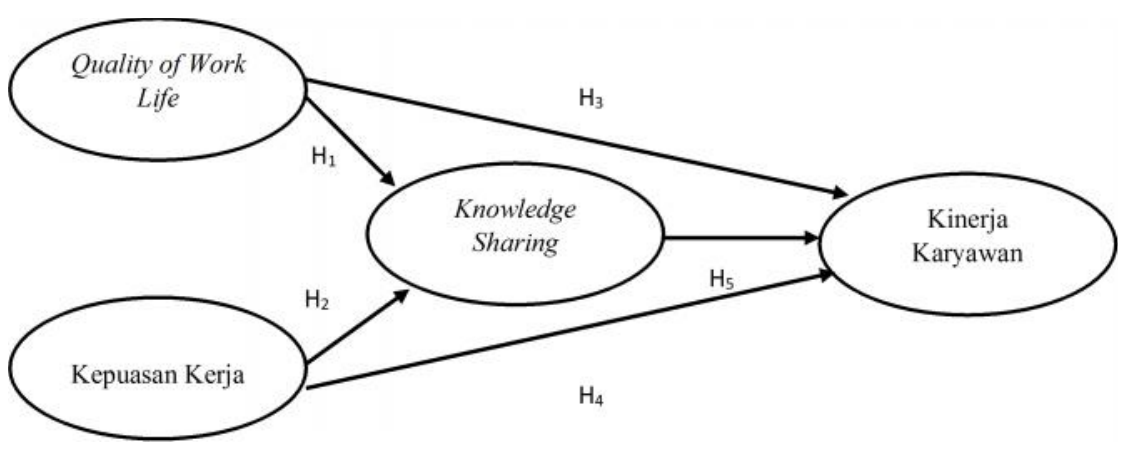

Gambar 1. Kerangka Konseptual Penelitian

\section{METODE PENELITIAN}

Penelitian ini berpendekatan kuantitatif, berjenis asosiatif. Data yang di peroleh dalam penelitian ini akan diolah dan dianalisis serta di dukung dengan teori agar dapat membuktikan hipotesis dan menjawab rumusan masalah rumusan masalah yang sudah dibuat sebelumnya.
Penelitian ini dilakukan di Swastika Bungalows Sanur yang beralamat di Jalan Danau Tamblingan No. 150 Sanur Denpasar Selatan. Pemilihan lokasi penelitian ini didasarkan adanya pertimbangan penerapan quality of work life, kepuasan kerja karyawan, knowledge sharing dan kinerja karyawan serta tersedianya data yang diperlukan dalam penelitian ini.

Tabel 1. Identifikasi Variabel

\begin{tabular}{|c|c|c|}
\hline VARIABEL & DEFINISI & INDIKATOR VARIABEL \\
\hline $\begin{array}{l}\text { Quality of Work Life } \\
\qquad\left(\mathrm{X}_{1}\right) \\
\text { Zin (2004) }\end{array}$ & $\begin{array}{l}\text { suatu keadaan terpenuhinya kebutuhan-kebutuhan } \\
\text { karyawan, adanya kesempatan bagi karyawan } \\
\text { untuk turut berperan menentukan cara bekerja dan } \\
\text { sumbangan yang dapat diberikan karyawan pada } \\
\text { organisasi }\end{array}$ & $\begin{array}{l}\text { 1) Partisipasi dalam pemecahan } \\
\text { masalah } \\
\text { 2) Sistem imbalan yang inovatif } \\
\text { 3) Restrukturisasi pekerjaan } \\
\text { 4) Perbaikan lingkungan kerja }\end{array}$ \\
\hline $\begin{array}{c}\text { Kepuasan Kerja } \\
\qquad\left(\mathrm{X}_{2}\right) \\
\\
\text { Fu et al. }(2011) \text {; Neubert } \\
(2015) ; \text { Shibru \& Darsan } \\
\text { (2011); Luthans } \\
(2011: 141) \text {; Sushama } \\
\text { Khanna (2011) }\end{array}$ & $\begin{array}{l}\text { emosi yang menyenangkan atau positif yang } \\
\text { dihasilkan dari penilaian terhadap pekerjaan atau } \\
\text { pengalaman kerja karyawan }\end{array}$ & $\begin{array}{l}\text { 1) Payment system } \\
\text { 2) Promotion } \\
\text { 3) Supervision } \\
\text { 4) Work it Self } \\
\text { 5) Work Condition }\end{array}$ \\
\hline $\begin{array}{l}\text { Knowledge Sharing } \\
\text { (Y1) }\end{array}$ & $\begin{array}{l}\text { proses pemindahan pengetahuan, keterampilan dan } \\
\text { keahlian antar karyawan dalam menunjang peran } \\
\text { rutin dan peningkatan kinerja }\end{array}$ & $\begin{array}{ll}\text { 1) Socialization } \\
\text { 2) Externalization } \\
\text { 3) Combination } \\
\text { 4) Internalization } \\
\text { 5) Individual factors } \\
\text { 6) Organizational factors } \\
\text { 7) Technology factors }\end{array}$ \\
\hline $\begin{array}{l}\text { Pradhan dan Jena (2017) } \\
\text { serta Mulya dan Japarianto } \\
\text { (2014) }\end{array}$ & $\begin{array}{l}\text { pencapaian hasil kerja karyawan atas pelaksanaan } \\
\text { tugas tertentu oleh seseorang atau sekelompok } \\
\text { orang dalam suatu organisasi, sesuai dengan } \\
\text { wewenang masing-masing, dalam rangka upaya } \\
\text { mencapai tujuan organisasi bersangkutan secara } \\
\text { legal tidak melanggar hukum dan sesuai dengan } \\
\text { moral dan etika. }\end{array}$ & $\begin{array}{l}\text { 1) Task Performance } \\
\text { 2) Contextual Performance } \\
\text { 3) Adaptive Performance }\end{array}$ \\
\hline
\end{tabular}

Sumber: Konsep yang dikembangkan dalam penelitian ini, 2018

Populasi dalam penelitian ini adalah jumlah karyawan di Swastika Bungalows Sanur sebanyak 60 orang. Pada penelitian ini seluruh karyawan Swastika Bungalows Sanur digunakan sebagai responden yang terdiri dari beberapa jabatan karyawan di Swastika Bungalows Sanur. Metode penarikan sampel yang digunakan dalam penelitian ini adalah metode sampel jenuh atau sensus, maka sampel yang digunakan adalah seluruh anggota populasi. Secara rinci sampel dalam penelitian ini disajikan pada Tabel 2. 
Tabel 2. Jumlah Karyawan Beserta Jabatan Karyawan di Swastika Bungalows Sanur

\begin{tabular}{clc}
\hline NO & \multicolumn{1}{c}{ JABATAN } & JUMLAH KARYAWAN \\
\hline 1. & Direktur/General Manager & 1 orang \\
2. & Operational Manager & 1 orang \\
3. & Assistance Manager/Financial & 1 orang \\
4. & Front Office, Bar \& Restaurant Supervisor & 1 orang \\
5. & Front Office & 6 orang \\
6. & Housekeeping & 23 orang \\
7. & Bar \& Restaurant & 9 orang \\
8. & Enggenering & 6 orang \\
9. & Gardener & 6 orang \\
10. & Security $\quad$ TOTAL SAMPEL & 4 orang \\
11. & Tukang (Harian) & 2 orang \\
\hline
\end{tabular}

Sumber : Swastika Bungalows Sanur, 2018

Analisis data dalam penelitian ini menggunakan pendekatan Partial Least Square (PLS) dengan pengujian mediasi SEM-PLS dengan metode VAF. Perhitungan VAF dilakukan dengan formula sebagai berikut:

$$
V A F=\underline{\text { Pengaruh Tidak Langsung }}
$$$$
\text { Pengaruh Total }
$$

\section{HASIL DAN PEMBAHASAN}

Terdapat tiga kriteria didalam penggunaan teknik analisis data dengan SmartPLS untuk menilai outer model yaitu convergent validity, discriminant validity, serta average variance extracted (AVE) dan composite reliability (Ghozali, 2008). Penelitian ini menggunakan batas minimal loading factor yaitu sebesar 0,5. Hasil pengolahan sebagaimana ditunjukkan pada Tabel 3. yang memperlihatkan bahwa nilai outer model telah memenuhi kriteria convergent validity dimana semua indikator memiliki loading factor di atas 0,50. Hal ini dapat disimpulkan bahwa konstruk mempunyai convergent validity yang baik.

Tabel 3. Outer Loadings

\begin{tabular}{|c|c|c|c|c|}
\hline & $\begin{array}{l}\text { Quality of Work } \\
\text { Life }\end{array}$ & Kepuasan Kerja & Knowledge Sharing & Kinerja Karyawan \\
\hline $\mathrm{X} 1.1$ & 0.871 & & & \\
\hline $\mathrm{X} 1.2$ & 0.909 & & & \\
\hline $\mathrm{X} 1.3$ & 0.768 & & & \\
\hline $\mathrm{X} 1.4$ & 0.864 & & & \\
\hline $\mathrm{X} 2.1$ & & 0.878 & & \\
\hline $\mathrm{X} 2.2$ & & 0.844 & & \\
\hline $\mathrm{X} 2.3$ & & 0.870 & & \\
\hline $\mathrm{X} 2.4$ & & 0.853 & & \\
\hline $\mathrm{X} 2.5$ & & 0.920 & & \\
\hline Y1.1 & & & 0.855 & \\
\hline Y1.2 & & & 0.899 & \\
\hline Y1.3 & & & 0.887 & \\
\hline Y1.4 & & & 0.885 & \\
\hline Y1.5 & & & 0.799 & \\
\hline Y1.6 & & & 0.844 & \\
\hline Y1.7 & & & 0.672 & \\
\hline $\mathrm{Y} 2.1$ & & & & 0.928 \\
\hline $\mathrm{Y} 2.2$ & & & & 0.951 \\
\hline Y2.3 & & & & 0.937 \\
\hline
\end{tabular}

Sumber : Data primer diolah, 2018 
Tabel 4. Cross Loadings

\begin{tabular}{lcccc}
\hline & $\begin{array}{c}\text { Quality of } \\
\text { Work Life }\end{array}$ & Kepuasan Kerja & $\begin{array}{c}\text { Knowledge } \\
\text { Sharing }\end{array}$ & $\begin{array}{c}\text { Kinerja } \\
\text { Karyawan }\end{array}$ \\
\hline X1.1 & $\mathbf{0 . 8 7 1}$ & 0.637 & 0.699 & 0.708 \\
X1.2 & $\mathbf{0 . 9 0 9}$ & 0.688 & 0.685 & 0.698 \\
X1.3 & $\mathbf{0 . 7 9 8}$ & 0.568 & 0.570 & 0.543 \\
X1.4 & $\mathbf{0 . 8 6 4}$ & 0.626 & 0.673 & 0.732 \\
\hline X2.1 & 0.673 & $\mathbf{0 . 8 7 8}$ & 0.701 & 0.723 \\
X2.2 & 0.583 & $\mathbf{0 . 8 4 4}$ & 0.551 & 0.599 \\
X2.3 & 0.667 & $\mathbf{0 . 8 7 0}$ & 0.661 & 0.696 \\
X2.4 & 0.629 & $\mathbf{0 . 8 5 3}$ & 0.676 & 0.678 \\
X2.5 & 0.662 & $\mathbf{0 . 9 2 0}$ & 0.678 & 0.716 \\
\hline Y1.1 & 0.636 & 0.645 & $\mathbf{0 . 8 5 5}$ & 0.694 \\
Y1.2 & 0.676 & 0.704 & $\mathbf{0 . 8 9 9}$ & 0.729 \\
Y1.3 & 0.669 & 0.671 & $\mathbf{0 . 8 8 7}$ & 0.696 \\
Y1.4 & 0.664 & 0.652 & $\mathbf{0 . 8 8 5}$ & 0.721 \\
Y1.5 & 0.651 & 0.688 & $\mathbf{0 . 7 9 9}$ & 0.765 \\
Y1.6 & 0.705 & 0.598 & $\mathbf{0 . 8 4 4}$ & 0.700 \\
Y1.7 & 0.498 & 0.399 & $\mathbf{0 . 6 7 2}$ & 0.561 \\
\hline Y2.1 & 0.752 & 0.752 & 0.769 & $\mathbf{0 . 9 2 8}$ \\
Y2.2 & 0.746 & 0.708 & 0.785 & $\mathbf{0 . 9 5 1}$ \\
Y2.3 & 0.725 & 0.749 & 0.794 & $\mathbf{0 . 9 3 7}$ \\
\hline
\end{tabular}

Sumber: Data primer diolah, 2018

Discriminant validity dari model pengukuran dengan reflektif indikator (faktor) dinilai berdasarkan crossloading pengukuran dengan konstruk. Data pada Tabel 4. menjelaskan bahwa nilai cross loading menunjukkan adanya discriminant validity yang baik. Hal tersebut dapat dilihat dari nilai korelasi indikator terhadap konstruknya (loading factor) lebih tinggi dibandingkan nilai korelasi indikator tersebut dengan konstruk lainnya.

Inner model menggambarkan hubungan antar variabel laten berdasarkan pada substantive theory. Hasil pengujian inner model dapa melihat hubungan antar konstruk dengan dengan cara membandingkan nilai signifikansi dan $R$-square dari model penelitian (Ghozali, 2008:42).

Tabel 5. Nilai R-Squares

\begin{tabular}{lc}
\hline & R Square \\
\hline Kinerja Karyawan & 0.775 \\
Knowledge Sharing & 0.668 \\
\hline
\end{tabular}

Sumber: Data primer diolah, 2018

Nilai $R$-square konstruk kinerja karyawan sebesar 0,775 pada Tabel 5. dapat diintepretasikan bahwa $77,50 \%$ variabilitas konstruk kinerja karyawan dijelaskan oleh konstruk quality of work life dan kepuasan kerja, sedangkan 22,50\% dijelaskan oleh variabel di luar model. Demikian juga dengan konstruk knowledge sharing dengan nilai R Square sebesar 0,668 mengandung arti bawah $66,80 \%$ variabilitasnya dijelaskan oleh quality of work life dan kepuasan kerja, sedangkan 33,20\% dijelaskan oleh variabel di luar model.

Pada model tersebut terdapat dua konstruk eksogen yaitu quality of work life dan kepuasan kerja dan ada dua konstruk endogen yaitu knowledge sharing dan kinerja karyawan. Keempat konstruk tersebut memiliki indikator masing - masing. 


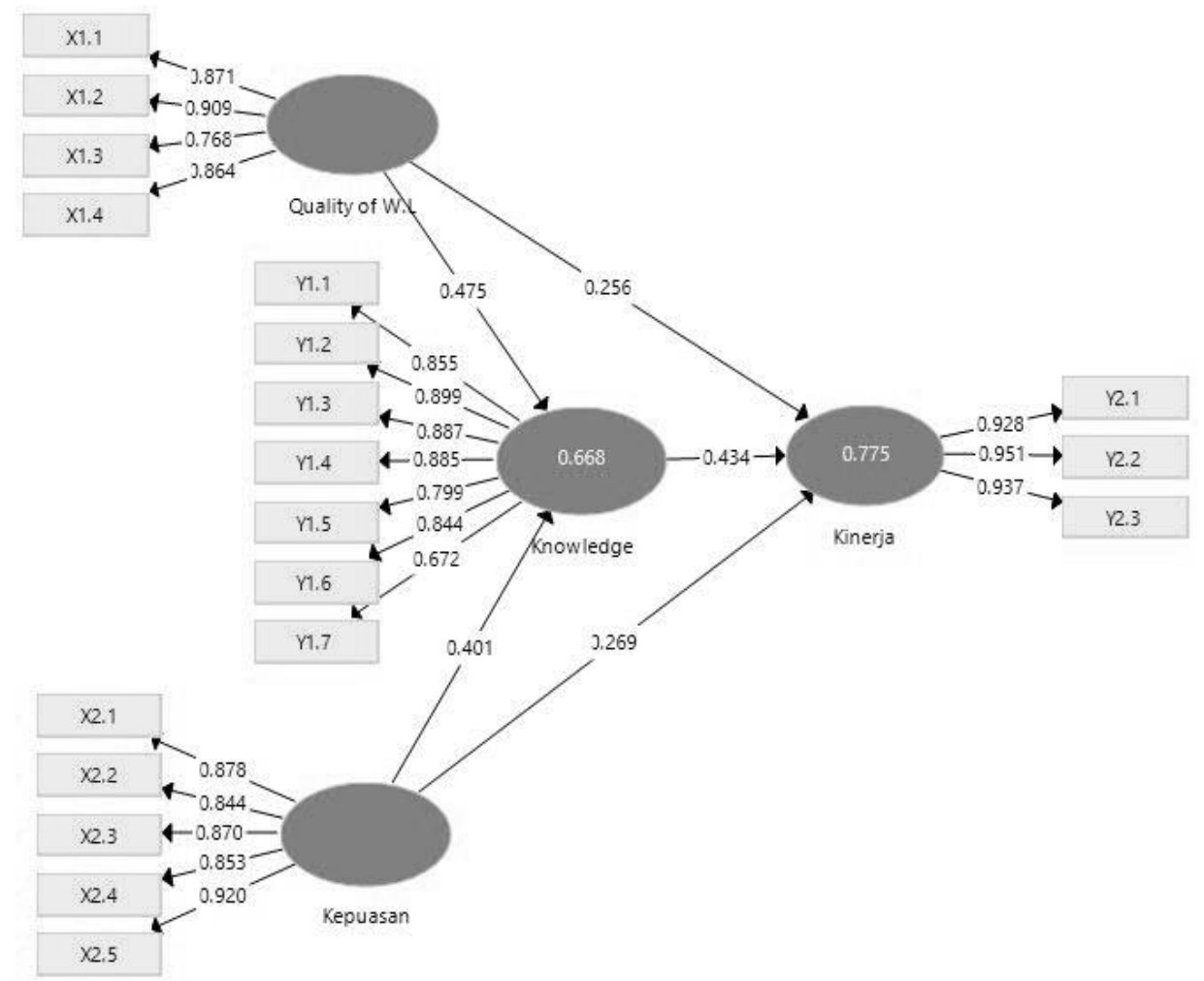

Gambar 2. Diagram Jalur Hasil Uji Hipotesis

Sumber: Data primer diolah, 2018

Tabel 6. Path Analisys

\begin{tabular}{lccc}
\hline & $\begin{array}{c}\text { Original } \\
\text { Sample } \\
(\mathrm{O})\end{array}$ & $\begin{array}{c}\text { T Statistics } \\
(\mid \mathrm{O} / \text { STERR } \mid)\end{array}$ & p Values \\
\hline Quality of W.L -> Knowledge & 0.475 & 4.146 & 0.000 \\
\hline Kepuasan -> Knowledge & 0.401 & 3.511 & 0.001 \\
\hline Quality of W.L -> Kinerja & 0.256 & 2.027 & 0.044 \\
\hline Kepuasan -> Kinerja & 0.269 & 2.158 & 0.032 \\
\hline Knowledge -> Kinerja & 0.434 & 2.750 & 0.006 \\
\hline
\end{tabular}

Sumber: Data primer diolah, 2018

Hasil pengujian hipotesis pertama menunjukkan bahwa pengaruh quality of work life terhadap knowledge sharing menunjukkan nilai koefisien jalur sebesar 0,475 dengan nilai P Value sebesar 0,000 . Nilai signifikansi atau $P$ Value sebesar 0,000 jauh lebih kecil dari 0,05 menunjukkan bahwa ada pengaruh yang signifikan antara variabel quality of work life terhadap knowledge sharing. Koefisen jalurnya menunjukkan bahwa quality of work life memberikan pengaruh positif terhadap knowledge sharing. Ini berarti semakin tinggi quality of work life yang dirasakan oleh karyawan, maka keinginan karyawan untuk berbagi pengetahuannya akan semakin tinggi. Sebaliknya semakin rendah quality of work life, maka keinginan karyawan untuk berbagi pengetahuannya semakin rendah.
Quality of work life terbukti mampu meningkatkan knowledge sharing karyawan jika penerimaan gaji atau upah yang tepat waktu, imbalan yang diterima sesuai pekerjaan yang dikerjakan, tunjangan yang diterima mencukupi kebutuhan, dan mendapatkan bonus dari perusahaan saat menyelesaikan tugas tepat pada waktunya, selain itu pemberikan tugas sesuai dengan jurusan pendidikan karyawan dan sistem kelompok kerja/ work group sangat membantu dalam karyawan bekerja. Hasil penelitian ini mengkonfirmasi beberapa hasil penelitian terdahulu seperti penelitian yang dilakukan oleh Masomi et al. (2014) dan Zadeh (2016) dimana hubungan antara quality of work life, life satisfaction dan knowledge management pada guru sekolah menengah kedua. Hasil penelitian 
ini menunjukkan bahwa ada hubungan langsung antara kualitas hidup ker quality of work life dengan knowledge management.

Hasil pengujian hipotesis pertama menunjukkan bahwa pengaruh kepuasan kerja terhadap knowledge sharing menunjukkan nilai koefisien jalur sebesar 0,401 dengan nilai $P$ Value sebesar 0,001 . Nilai signifikansi atau P Value sebesar 0,001 jauh lebih kecil dari 0,05 menunjukkan bahwa ada pengaruh yang signifikan antara variabel kepuasan kerja terhadap knowledge sharing. Koefisen jalurnya menunjukkan bahwa kepuasan kerja memberikan pengaruh positif terhadap knowledge sharing. Ini berarti semakin tinggi kepuasan kerja karyawan, maka keinginan karyawan berbagi pengetahuan yang dimilikinya akan semakin tinggi. Sebaliknya semakin rendah kepuasan kerja karyawan, maka keinginan karyawan berbagi pengetahuan yang dimilikinya akan semakin rendah.

Kepuasan Kerja yang diukur dengan perusahaan menjamin jenjang karir karyawan dimasa depan, memberikan kesempatan kepada karyawan untuk ikut serta berdiskusi, selalu memberikan kompensasi untuk karyawan yang berprestasi, dan selalu memperhatikan keamanan kerja karyawan terbukti mampu meningkatkan knowledge sharing. Hasil penelitian ini mengkonfirmasi hasil penelitian terdahulu seperti penelitian yang dilakukan oleh Suliman dan AlHosani (2014), Horvat et al. (2015) dan hasil studi lain yang dilakukan oleh Abdullah, Ismail, dan Idrus (2015) menemukan bahwa terdapat hubungan langsung antara kepuasan kerja dengan praktek berbagai pengetahuan antara akademisi di Malaysia. Hal ini memberikan implikasi bahwa kepuasan kerja membuat karyawan mau berbagi pengetahuan terhadap karyawan lain.

Hasil pengujian hipotesis pertama menunjukkan bahwa pengaruh quality of work life terhadap kinerja karyawan menunjukkan nilai koefisien jalur sebesar 0,256 dengan nilai $P$ Value sebesar 0,044. Nilai signifikansi atau P Value sebesar 0,044 jauh lebih kecil dari 0,05 menunjukkan bahwa ada pengaruh yang signifikan antara variabel quality of work life terhadap kinerja karyawan. Koefisen jalurnya menunjukkan bahwa quality of work life memberikan pengaruh positif terhadap kinerja karyawan. Ini berarti semakin tinggi quality of work life yang dirasakan oleh karyawan, maka kinerja karyawan akan semakin tinggi. Sebaliknya semakin rendah quality of work life, maka kinerja karyawan semakin rendah.
Variabel quality of work life terbukti mampu meningkatkan kinerja karyawan jika tunjangan yang diterima mencukupi kebutuhan, dan mendapatkan bonus dari perusahaan saat menyelesaikan tugas tepat pada waktunya. Hasil penelitian ini mengkonfirmasi hasil penelitian terdahulu yang dilakukan oleh Frediyan, Nurul, dan Nuraida. (2017) dan penelitian oleh (Fathiyah dan Alex, 2017) mengungkapkan hubungan antara quality of work life dengan kepuasan kerja dan kinerja karyawan secara parsial adalah positif dan signifikan.

Hasil pengujian hipotesis pertama menunjukkan bahwa pengaruh kepuasan kerja terhadap kinerja karyawan menunjukkan nilai koefisien jalur sebesar 0,269 dengan nilai $P$ Value sebesar 0,032 . Nilai signifikansi atau P Value sebesar 0,032 jauh lebih kecil dari 0,05 menunjukkan bahwa ada pengaruh yang signifikan antara variabel kepuasan kerja terhadap kinerja karyawan. Koefisen jalurnya menunjukkan bahwa kepuasan kerja memberikan pengaruh positif terhadap kinerja karyawan. Ini berarti semakin tinggi kepuasan kerja yang dirasakan oleh karyawan, maka kinerja karyawan akan semakin tinggi. Sebaliknya semakin tinggi kepuasan kerja karyawan, maka kinerja karyawan semakin tinggi.

Kepuasan Kerja yang diukur dengan penerimaan gaji sesuai dengan posisi jabatan karyawan, menjamin jenjang karir karyawan dimasa depan, memberikan kesempatan kepada karyawan untuk ikut serta berdiskusi, selalu memberikan kompensasi untuk karyawan yang berprestasi, dan selalu memperhatikan keamanan kerja karyawan terbukti mampu meningkatkan knowledge sharing. Hasil penelitian ini mengkonfirmasi hasil penelitian terdahulu yang dilakukan oleh Funmilola, Sola, and Olusola (2013), Arsiyati (2013) dan penelitian oleh Triyono (2011) mengatakan bahwa dimensi kepuasan kerja yang terdiri dari pay, supervision, promotion, work it self dan work condition berkontribusi positif dan signifikan terhadap kinerja karyawan.

Hasil pengujian hipotesis pertama menunjukkan bahwa pengaruh knowledge sharing terhadap kinerja karyawan menunjukkan nilai koefisien jalur sebesar 0,269 dengan nilai P Value sebesar 0,434. Nilai signifikansi atau P Value sebesar 0,006 jauh lebih kecil dari 0,05 menunjukkan bahwa ada pengaruh yang signifikan antara variabel knowledge sharing terhadap kinerja karyawan. Koefisen jalurnya menunjukkan bahwa knowledge sharing memberikan pengaruh positif terhadap kinerja 
karyawan. Ini berarti semakin tinggi knowledge sharing yang terjadi, maka kinerja karyawan akan semakin tinggi. Sebaliknya semakin rendah knowledge sharing yang terjadi, maka kinerja karyawan semakin rendah.

Knowledge sharing yang diukur dengan penerimaan gaji sesuai dengan beban pekerjaan karyawan, berbagi ide/gagasan pada saat rapat, berbagi ide/gagasan kepada rekan kerja untuk peningkatan kinerja, membuat kesimpulan untuk memfasilitasi pada saat rapat terbukti mampu meningkatkan kinerja karyawan. Hasil penelitian ini mengkonfirmasi hasil penelitian terdahulu yang dilakukan oleh Akram dan Bokhari (2011), Ozlen (2015) Wang dan Wang (2012), Masa'deh et al. (2015) juga menemukan hubungan positif dan signifikan antara knowledge sharing dan kinerja karyawan. Untuk membangun knowledge sharing perlu dibuat lingkungan yang mau saling berbagi antar karyawan memiliki rasa memiliki dan rasa tanggungjawab terhadap kinerja pribadi maupun kinerja kolega.

Tabel 7. Indirect Effect

\begin{tabular}{lccc}
\hline & $\begin{array}{c}\text { Original } \\
\text { Sample } \\
(\mathrm{O})\end{array}$ & $\begin{array}{c}\text { T Statistics } \\
(|\mathrm{O} / \mathrm{STERR}|)\end{array}$ & $\begin{array}{c}\mathrm{P} \\
\text { Values }\end{array}$ \\
\hline Quality of W.L -> Knowledge $->$ Kinerja & 0.206 & 2.239 & 0.026 \\
\hline Kepuasan -> Knowledge -> Kinerja & 0.174 & 2.005 & 0.046 \\
\hline Sumber : Data primer diolah, 2018 & & &
\end{tabular}

Tabel 7. menunjukkan besarnya koefisien pengaruh tidak langsung quality of work life terhadap kinerja karyawan melalui knowledge sharing adalah sebesar 0,206 dengan signifikansi sebesar 0,026. Nilai signifikansi sebesar 0,026 lebih kecil dari 0,05. Pengujian variabel pemediasi knowledge sharing dilakukan dengan menghitung nilai Variance Accounted For (VAF) yang dapat dilihat pada Tabel 8 .

Tabel 8. Perhitungan VAF Hubungan Tidak Langsung Variabel Quality of Work Life terhadap Kinerja Karyawan Melalui Knowledge Sharing

\begin{tabular}{lll}
\hline & \multicolumn{1}{c}{ Hubungan Variabel } & Koefisien \\
\hline Pengaruh tidak langsung & quality of work life -> knowledge sharing & 0.475 \\
\hline & knowledge sharing -> kinerja karyawan & 0.434 \\
\hline Pengaruh Langsung & Pengaruh tidak langsung = 0.475x0.434 & 0.206 \\
\hline Pengaruh Total & quality of work life -> kinerja karyawan & 0.256 \\
\hline VAF & quality of work life -> kinerja karyawan $(0.256+0.206)$ & 0.462 \\
\hline
\end{tabular}

Sumber: Data primer diolah, 2018

Dari hasil perhitungan pada Tabel 8. dapat diartikan bahwa peran knowledge sharing sebagai pemediasi mempunyai nilai VAF sebesar 0,446 $(44,6 \%)$. Hasil ini menunjukkan bahwa variabel knowledge sharing mempunyai peran sebagai pemediasi antara quality of work life dan kinerja karyawan (partial mediation), sehingga hipotesis yang menyatakan bahwa knowledge sharing berperan sebagai mediasi hubungan antara quality of work life dengan kinerja karyawan terbukti.

Berdasarkan hasil analisis data secara statistik membuktikan bahwa knowledge sharing mampu memediasi secara positif dan signifikan pengaruh quality of work life terhadap kinerja karyawan.
Hasil penelitian ini mengkonfirmasi hasil penelitian terdahulu yang dilakukan oleh Dharma (1985, dalam Arisman, 2007) kinerja adalah suatu yang dikerjakan atau produk/jasa yang dihasilkan atau atau diberikan seseorang atau sekelompok orang.

Tabel 7. menunjukkan besarnya koefisien pengaruh tidak langsung kepuasan kerja terhadap kinerja karyawan melalui knowledge sharing adalah sebesar 0,174 dengan signifikansi sebesar 0,046 . Nilai signifikansi sebesar 0,046 lebih kecil dari 0,05 . Pengujian variabel pemediasi knowledge sharing dilakukan dengan menghitung nilai Variance Accounted For (VAF) yang dapat dilihat pada Tabel 9. 
Tabel 9. Perhitungan VAF Hubungan Tidak Langsung Variabel Quality of Work Life terhadap Kinerja Karyawan Melalui Knowledge Sharing

\begin{tabular}{lll}
\hline & \multicolumn{1}{c}{ Hubungan Variabel } & Koefisien \\
\hline Pengaruh tidak langsung & kepuasan kerja -> knowledge sharing & 0.401 \\
\hline & knowledge sharing -> kinerja karyawan & 0.434 \\
\hline & Pengaruh tidak langsung = 0.401x0.434 & 0.174 \\
\hline Pengaruh Langsung & kepuasan kerja -> kinerja karyawan & 0.269 \\
\hline Pengaruh Total & kepuasan kerja -> kinerja karyawan $(0.269+0.174)$ & 0.443 \\
\hline VAF & Pengaruh Tidak Langsung/Pengaruh Total $(0.174 / 0.443)$ & 0.393 \\
\hline
\end{tabular}

Sumber : Data primer diolah, 2018

Dari hasil perhitungan pada Tabel 9. dapat diartikan bahwa peran knowledge sharing sebagai pemediasi mempunyai nilai VAF sebesar 0,393 $(39,3 \%)$. Hasil ini menunjukkan bahwa variabel knowledge sharing mempunyai peran sebagai pemediasi antara kepuasan kerja dan kinerja karyawan (partial mediation), sehingga hipotesis yang menyatakan bahwa knowledge sharing berperan sebagai mediasi hubungan antara kepuasan kerja dengan kinerja karyawan terbukti.

Berdasarkan hasil analisis data secara statistik membuktikan bahwa knowledge sharing mampu memediasi secara positif dan signifikan pengaruh kepuasan kerja terhadap kinerja karyawan. Hasil penelitian ini mengkonfirmasi hasil penelitian terdahulu yang dilakukan oleh Saeed (2016) dan penelitian Fadlallh (2015) bahwa ada pengaruh positif dan signifikan secara statistik antara faktor kepuasan kerja dengan kinerja karyawan melalui knowledge sharing.

\section{SIMPULAN DAN SARAN}

Hasil penelitian mendukung semua hipotesis yang diajukan yaitu quality of work life berpengaruh positif terhadap knowledge sharing. Kepuasan kerja berpengaruh positif terhadap knowledge sharing. Quality of work life berpengaruh positif terhadap kinerjaa karyawan. Kepuasan kerja berpengaruh positif terhadap kinerja karyawan. Knowledge sharing berpengaruh positif terhadap kinerja karyawan. Knowledge sharing mampu memediasi pengaruh quality of work life terhadap kinerja karyawan. Knowledge sharing mampu memediasi pengaruh kepuasan kerja terhadap kinerja karyawan.

Beberapa saran yang dapat dipergunakan sebagai bahan pertimbangan bagi manajemen Swastika Bungalows Sanur dalam menentukan kebijakan di masa yang akan datang terutama yang berkaitan dengan quality of work life, kepuasan kerja, knowledge sharing dan kinerja karyawan. Organisasi sebaiknya lebih memperhatikan faktor aesthetic lingkungan kerja terutama dengan menghargai kerja keras karyawan seperti memperhatikan suasana kerja yang nyaman sehingga dapat membangkitkan semangat kerja karyawan dan kenyamanan karyawan dalam menjalankan pekerjaan. Pihak manajemen agar dapat memberikan kesempatan promosi jabatan, dukungan para supervisor, supervisor selalu memberikan motivasi, kepedulian dan keadilan para supervisor terhadap bawahannya, menjaga kenyamanan bekerja, dan selalu memperhatikan kepedulian rekan kerja, kepuasan gaji dimana dalam penerimaan gaji yang sesuai dengan beban pekerjaan, meningkatkan pemberian insentif disesuaikan dengan kinerja dan peraturan yang berlaku, meningkatkan pemberian tunjangan disesuaikan dengan beban kerja dan memperbaiki sistem tunjangan yang diberikan sesuai dengan kondisi organisasi.

\section{REFERENSI}

Abdullah, Nu. J.S., Ismail, I.A., and Idrus, Khairuddin. (2015). Organizational Antecedent with Job Satisfaction, Work Performance as Mediator and Knowledge Sharing Praktices among Academician at Malaysia Research Universities. International Journalu of Economics and Financial, 5, 57-62.

Ahmad, Habib., Khursheed Ahmad., dan Idrees Ali Shah. (2010). Relationship between Job Satisfaction, Job Performance, Attitude toward Work and Organizational Commitment. European Journal of Social Sciences, 18(2), 257-267

Aslam, Astri., Asri Laksmi Riani., dan Gunawan Pamudji W. (2013). Pengaruh Perilaku Kerja, Lingkungan Kerja, Dan Interaksi Sosial Terhadap Kepuasan Kerja Dengan Motivasi Sebagai Variabel Pemediasi (Studi Pada Staf 
Rumah Sakit Umum Daerah Pandan Arang Boyolali). Prosiding Seminar Nasional Perkembangan Terkini Sains Farmasi Dan Klinik Iii. ISSN: 2339-2592.

Astitiani, Ni Luh Putu Surya., dan Ida Bagus Ketut Surya. (2016). Pengaruh Quality Of Work Life Terhadap Motivasi Kerja Dan Kepuasan Kerja Karyawan. Matrik: Jurnal Manajemen, Strategi Bisnis dan Kewirausahaan, 10(2), 156-167.

Belias, D., Koustelios, A., George, V., and Labros, S. (2015). Organizational Culture and Job Satisfaction of Greek Banking Institutions. Procedia - Social and Behavioral Sciences, 175,314-323.

Borman, W.C. dan Motowidlo, S.J. (1993). Expanding The Criterion Domain to Include Elements of Extra-role Performance, dalam Schmitt, N. \& Borman, W.C (editors). Personnel Selection in Organizations. San Francisco: Jossey-Bass.

Cascio, Wayne F. (2013). Managing Human Resources, Productivity, Quality of Work Life, Profits. Ninth Edition. America : The MacGraw Hill Company.

Campbell, J. P. (1990). Modeling the performance prediction problem in industrial and organizational psychology. In M. D. Dunnette \& L. M. Hough (Eds.), Handbook of industrial and organizational psychology. Palo Alto: Consulting Psychologists Press, 1, 687-732.

Chandra, T dan Priyono. (2016). The Influence of Leadership Styles, Work Environment and Job Satisfaction of Employee PerformanceStudies in the School of SMPN 10 Surabaya. International Education Studies, 9(1), 131

Davis, Newstorm. (2006) . Perilaku Dalam Organisasi, Erlangga, Jakarta.

Fadlallh, A.W.A. (2015). Impact of Job Satisfaction on Employees Performance an Application on Faculty of Science and Humanity Studies University of Salman Bin Abdul-Aziz-Al Aflaj. International Journal of Innovation and Research in Educational Sciences, 2, 26-32.

Fathiyah, Ahmad Firdaus., dan Alex Kurnia Putra. (2017). Pengaruh Komitmen Kerja Dan Quality Of Work Life (Qwl) Terhadap Kepuasan Kerja Dan Dampaknya Terhadap Kinerja Karyawan Pt. Indofood Cbp Sukses Makmur Cabang Jambi. J-Mas, 2(1), 105-120
Frediyan, Satya Muda., Nurul Ummi., dan Nuraida Wahyuni. (2017). Pengaruh Quality Of Work Life (Qwl) Terhadap Produktivitas Kerja Karyawan Menggunakan Structural Equation Modelling (Sem) (Studi Kasus: Pt. Krakatau Tirta Industri). Jurnal Teknik Industri, 5(2), 133-140

Fu, Weihui., and Deshpande Satish P. (2014). The Impact of Caring Climate, Job Satisfaction and Organizational Commitment on Organizational Performance in a China's Insurance Company. Journal Business Ethics, 124, 339-349.

Funmilola, O.F., Sola, K.T., and Olusola. (2013). Impact of Job Satisfaction Dimensions on Job erformance in a Small and Medium Enterprise in Ibadan, South Western, Nigeria. Interdisciplinary Journal of Contemporary Research in Business, 4(11), 509-521.

George, J. M., and Jones, G. R. (2005). Essentials of Managing Organizational Behavior, 4th ed., New Jersey: Upper Saddle River.

Grant, R.M. (1991). The Resource Based Theory of Competitive Advantage: Implications for Strategy Formulation. California Management Review (spring), 114-135.

Griffin M. A., Neal A., dan Parker S. K. (2007). A new model of work role performance: positive behavior in uncertain and interdependent contexts. Acad Manag J, 50, 327-347.

Herjianto, Puji. (2008). Kajian Tentang Knowledge Sharing Secara Berkelanjutan Sebagai Media Untuk Meningkatkan Kualitas Performance Organisasi diakses dari http isjd.pdii.lipi.go.id/ admin/jurnal/22088897.pdf

Idrus, M. (2006). Implikasi Organisasi Terhadap Kepuasan Kerja Dan Kualitas Kehidupan Kerja Karyawan. Jurnal Psikologi Universitas Diponogoro, 3(1), 94-106.

Istijanto, Oei. (2010). Riset Sumber Daya Manusia. Jakarta: PT. Gramedia Pustaka. Utama.

Jordan, J., dan Jones, P. (1997). Assessing your company's knowledge management style. Long Range Planning, 30(3), 392 - 398.

Kermansaravi, Fatihe., Ali Navidian., Shahindokht Navabi Rigi., and Fariba Yaghoubinia. (2015). The Relationship between Quality Of Work Life And Job Statisfaction Of Faculty Members In Zahedan University Of Medical Sciences. Global Journal of Health Sciences, 7(2). 
Khorsandi, M., Jahani, F., Rafie, M., and Farazi, A. (2010). Health - Related Quality Of Life In Staff And Hospital Personnel Of Arak University Of Medical Sciences In 2009. Journal of Arak Medical University, 13(1), 40-48 (Persian).

Kismono, G., Reni R., dan John, S. (2013). Faktorfaktor demografik (jenis kelamin, usia, status pernikahan, dukungan domestik) penentu konflik pekerjaan dan keluarga dan intensi keluar karyawan: studi pada industri perbankan Indonesia. Jurnal Siasat Bisnis, 17(2), 208-224

Kurniawan, Fajar. (2018). Pengaruh Knowledge Management dan Lingkungan Kerja Terhadap Kinerja Karyawan Dengan Kepuasan Kerja Sebagai Variabel Intervening (Studi Pada Tenaga Kependidikan Universitas X Yogyakarta). Tesis. Fakultas Ekonomi Program Studi Magister Manajemen Universitas Islam Indonesia

Lin, Hsiu-Fen. (2007). Knowledge Sharing and Firm Inovation Capability: An Empirical Study. International Journal of manpower, 28(3/4), 315-332.

Locke, E. (1976). The Nature and Couse of Job satisfaction. In: M. Dunnete (Ed), Handbook of Industrial and Organizational Psycology. Chicago: Rand McNally.

Masa'deh, R. (2016). The Role of Knowledge Management Infrastructure in Enhancing Job Satisfaction at Aqaba Five Star Hotels in Jordan. Scientific Research Publishing Journal, 8, 219

Menguc, B., Auh, S., and Ozane, L. (2010). The Interractive Effect of Internal and External Factors on a Proactive Environmental Strategy and its Infuence on a firm Performance. Journal of Business Ethics, 94, 279-298.

Mulya, A. C., dan Japarianto, E. (2014). Analisa Persepsi Pelanggan Terhadap Kinerja Agen Properti dan Pengaruhnya Terhadap Kepercayaan di Surabaya. Jurnal Manajemen Pemasaran Petra, 2(1), pp.1-8.

Murti, Harry., dan Veronika Agustini Srimulyani. (2013). Pengaruh Motivasi Terhadap Kinerja Pegawai Dengan Variabel Pemediasi Kepuasan Kerja Pada PDAM Kota Madiun. Jurnal Riset Manajemen \& Akuntansi, 1(1).

Ndlela, L.T., dan Toit, A. (2001). Establishing a knowledge management programme for competitive advantage in an enterprise. International journal of information management, 21, 151-165.
Nekouei. (2014). Quality of Work Life and Job Satisfaction among Employee in Government Organizations in IRAN. Journal of Basic and Applied, 4(1).

Nelson, R. R., dan Winter, S. G. (1982). An evolutionary theory of economic change. Boston: Belkman Press.

Neubert, Mitchell J., and Halbesleben, Katie. (2015). Called to Commitment: An Examination of Relationship between Spiritual Calling, Job Satisfaction and Organizational Commitment. Journal Business Ethics, 10(1007), 859-872.

Nezafati, N. Afrazeh, A. \& Jalali, S.M.J. (2009). A dynamic model for measuring knowledge level of organizations based on Nonaka and Takeuchi model. Scientific Research and Essay, 40(5), 531-542

Nonaka, I., and Takeuchi, H. (1995). The Knowledge Creating Company: How Japanese Companies Create the Dynamic of Innovation. New york: Oxford University Press.

Ozlen, Muhammed Kursad. (2015). Knowledge Sharing Behavior of Bosnian Enterprise. Accounting and Management Information System, 14(3), 575-590.

Pradhan, S., dan LK Jena. (2017). Effect of abusive supervision on employee's intention to quit and the neutralizing role of meaningful work in Indian IT organizations. International Journal of Organizational Analysis, 25(5), 825-838.

Pugna, I. B., and Boldeanu, D.-M. (2014). Factors Affecting Establishment of an Institutional Knowledge Manajemen Culture - a Study of Organizational Vision. Accounting and Management Information System, 13(3), 559-583.

Rauch, A., frese, M., and Utsch, A. (2005). Effect of Human Capital and Long Term Human Resources Development and utilization on Employement Growth of Small Scale business: an Causal Analysis. Enterpreneurship Theory an Practices, 681-698.

Robbins, Steven P., dan Timothy. (2013). Organizational Of Bahvior. $8^{\text {th }}$ Edition, Mcgraw-Hill, Irwin.

Saeed, M.S. (2016). The Impact of Job Satisfaction and Knowledge Sharing on Employee Performance. Journal of Resources Development and Management, 21, 16

Sani, Achmad. (2013). Role of Procedural Justice, Organizational Commitment and Job satisfaction on Job Performance: The Mediating Effect of organizational Citizen Behavior. International 
14 Matrik: Jurnal Manajemen, Strategi Bisnis dan Kewirausahaan Vol. 13, No. 1, Februari 2019

Journal of Business and Management, 8(15), 57-67.

Suarli, S., dan Bahtiar. (2010). Manajemen Keperawatan Dengan Pendekatan Praktik. Jakarta: Erlangga.

Sugiyono. (2014). Metode Penelitian Bisnis

Kuantitatfi, Kualitatif dan R\&D. Bandung: CV Alfabeta.

Swapna, M., and S. Gomathi. (2013). A Study On The Interplay Between The Constructs Of Quality Of Work Life: With Special Reference To IT Profesionals In Bangalore City. Asian Social Sciences, 9(9).

Teece, D.J., Pisano, G., and Shuen, A. (1997). Dynamic Capability and Strategic Management.
Strategic Management Journal, 18(7), 509533

Walton, R. E. (1998). Quality Of Work Life, What Is It?. Sloan Management Review Journal, 11-21.

Wang, S., and Noe, R.A. (2010). Knowledge Sharing: a review and directions for future research. Human Resource Management Review, 20, 115-131.

Zin, R.M. (2004). Perception Of Professional Engineers Toward Quality Of Work Life And Organizational Commitment A Case Study. Gadjah Mada International Journal of Business, 6(3), 323-334. 